\title{
Case Study: Flow Measurement and Control in Walker River Irrigation District
}

\author{
Sierra Layous, P.E., ${ }^{1}$ Stuart Styles, P.E., D.Engr., M. ASCE, ${ }^{2}$ \\ and Robert Bryan ${ }^{3}$
}

${ }^{1}$ Senior Engineer, Irrigation Training and Research Center, 1 Grand Ave, Bldg 8A, California Polytechnic State Univ., San Luis Obispo, CA, 93407, e-mail: slayous@calpoly.edu ${ }^{2}$ Director, Irrigation Training and Research Center, 1 Grand Ave, Bldg 8A, California Polytechnic State Univ., San Luis Obispo, CA, 93407, e-mail: sstyles@calpoly.edu ${ }^{3}$ General Manager, Walker River Irrigation District, 410 N. Main Street, Yerington, NV, 894472322, e-mail: bert@wrid.us

\begin{abstract}
Walker River Irrigation District (WRID) is located in Nevada around the community of Yerington and contains approximately 95,000 hectares (235,000 acres), 32,000 hectares (80,000 acres) of which are irrigated. The district operates a canal system centered around the three forks of the Walker River. Starting in 2009, the district has worked with the Irrigation Training and Research Center (ITRC) to modernize its system by improving the accuracy of the measured diversions from the Walker River and enhancing the real-time control capabilities of the water managers. A "package” was developed for the headworks of canals diverting water from the river, consisting of a combination of the following based on site conditions: a Replogle flume for flow measurement, a self-contained motorized slide gate(s) in a district-standard configuration, a remote terminal unit (RTU) for automatic control of the slide gate(s) and communication with the office base station in Yerington (SCADA), an ITRC flap gate and modifications to the existing spill structure, sediment control features, and off-grid solar power for the entire site. To date, variations of the package have been successfully applied at over ten sites throughout the district, with more sites in progress and planned for the future. Modifications to the initial package have been made over the last eight years to reflect advances in technology, challenges found at completed sites, as well as additional needs identified at the sites. The district plans on continuing the modernization based on the success of the program to date.
\end{abstract}

\section{INTRODUCTION}

The recommendations in this paper are guided by successful experiences with many irrigation districts in the western US in the transformation of old, manually-operated canal systems into modern projects operated with high levels of water delivery service and a clear accounting of water diversions. A successful irrigation modernization program must maintain an appropriate balance of technical upgrades and management sustainability. In the case of WRID, the motivation for irrigation modernization is the need for robust and cost-effective measurement and control of flows diverted from the Walker River. This paper focuses specifically on the "package” of components used at various sites throughout the district to locally measure and automatically maintain flow rates at turnouts, and remotely monitor and manage those flow rates with a Supervisory Control and Data Acquisition (SCADA) system. 
Figure 1 shows a location map of completed and proposed sites in the Walker River Basin. Full "package" sites (automation and SCADA) are indicated with a thick black border. Other sites include portions of the "package" (e.g., some of the components are installed but the site is not fully automated) as well as other projects. A discussion of the other projects (pipelines, reservoirs) within the district is included in a later section of this paper.

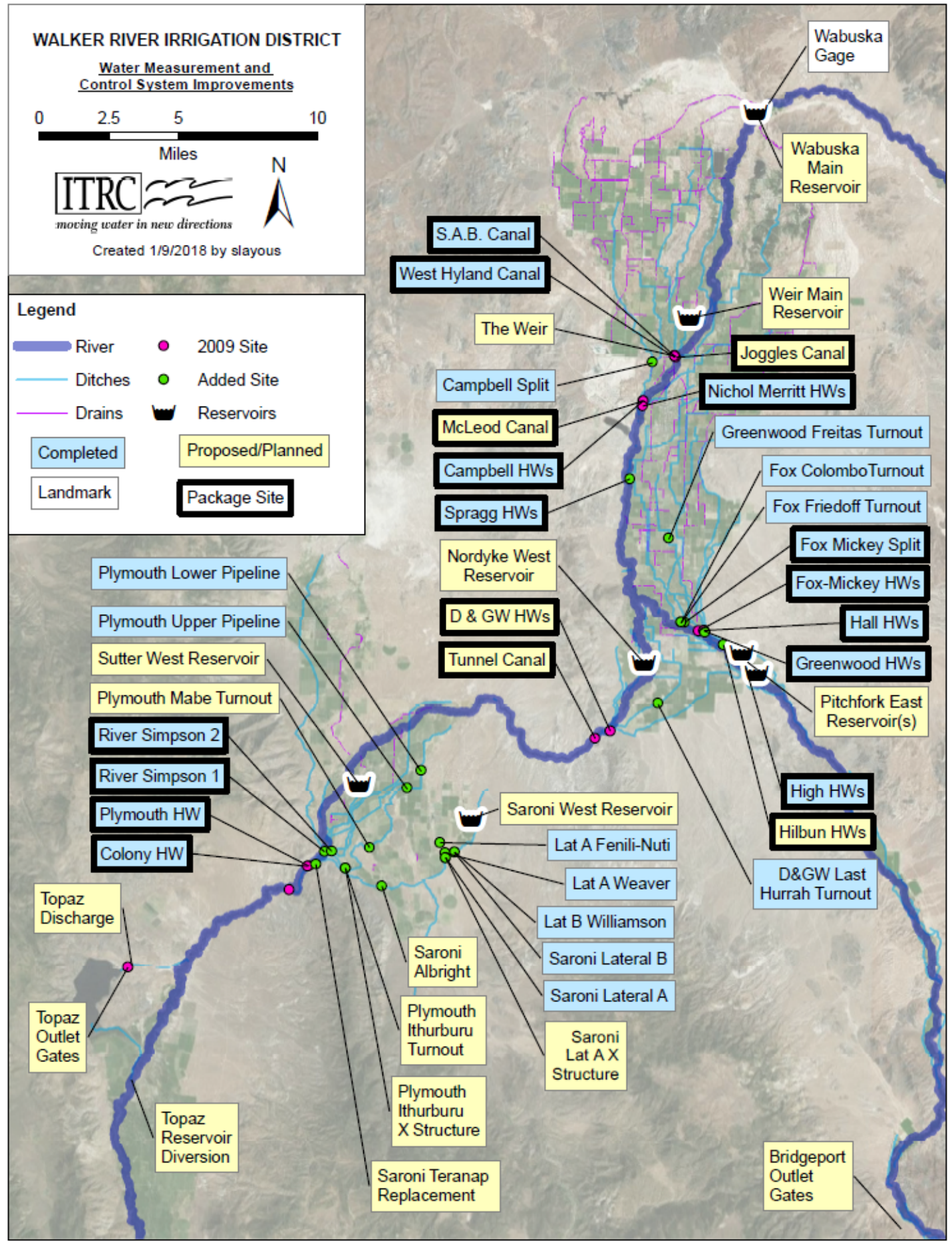

Figure 1. Irrigation turnouts within the Walker River Basin (water flows south to north in river) 


\section{PRE-MODERNIZATION WATER OPERATIONS}

WRID operates five divisions covering approximately 32,000 hectares (80,000 acres) in Nevada and California. There are approximately 50 sub-systems using irrigation water supplied in part by WRID including community ditch systems.

WRID's pre-modernization system operations were characterized as follows (refer to Figure 2):

- The headworks of a typical canal usually consisted of one or two wooden slide gates with manually-operated steel lifting mechanisms (with hand wheels). One or two separate sets of slide gates were installed in some sites - with the downstream one (if it existed) operating as flow control. The canals had various types of spill structures; if located upstream of a Parshall flume, the structures maintained a desired flow rate in the canal through manual adjustments to the spill settings.

- Push-up diversion dams were built across the Walker River with large native rocks and streambed materials at the diversion points. This maintained a minimum hydraulic head across the canal headworks when river levels were low.

- The diversion channels at a canal headworks typically had a continuous return flow structure (of various designs) that served somewhat to keep water levels constant at the flow control gates by returning a portion of the diverted flow. Some sites used Danaidean gates (shown in Figure 3) for upstream water level control.

- The main conveyance canals had flashboard check structures of varying designs for maintaining canal water levels for turnouts.

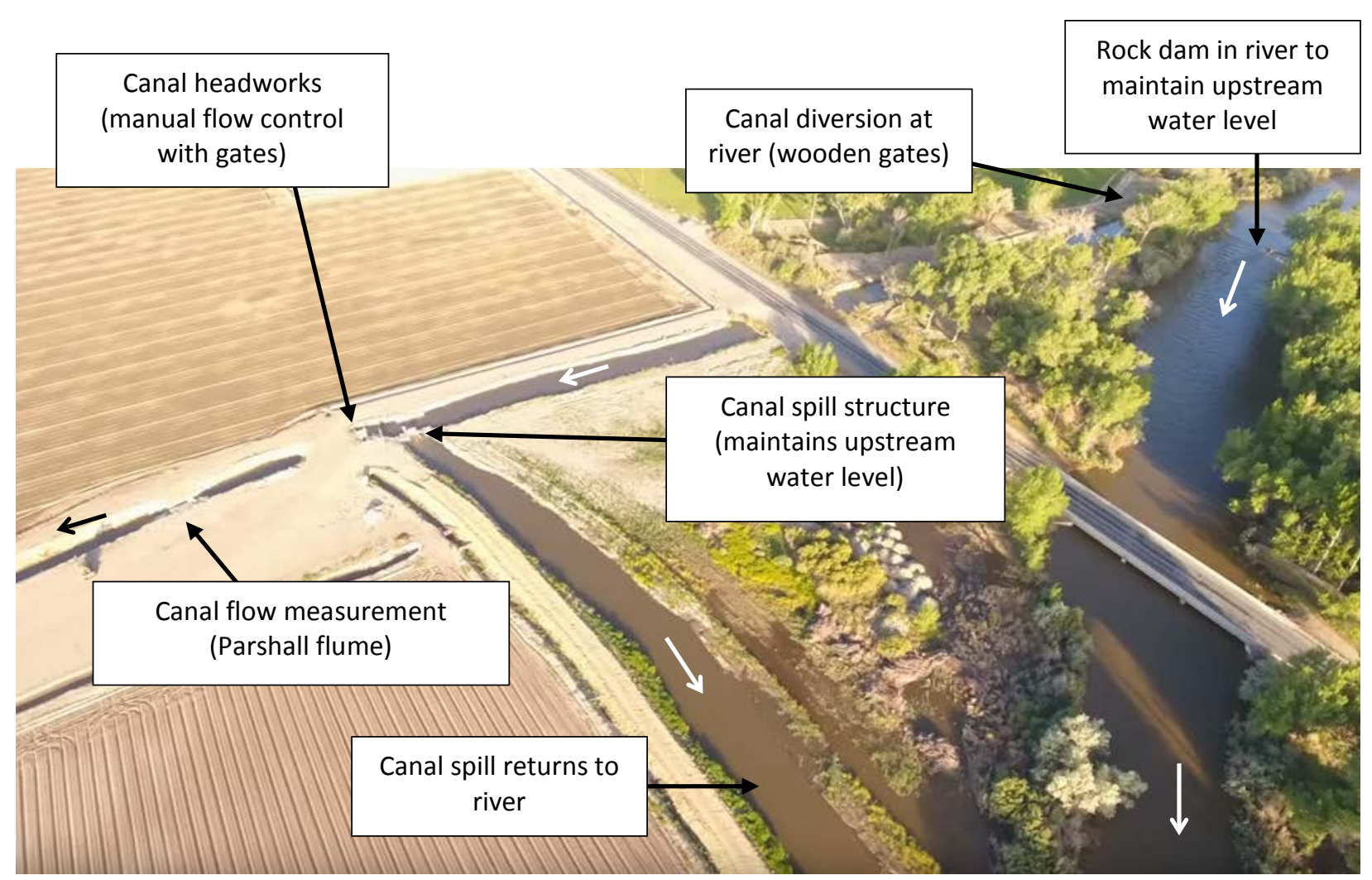

Figure 2. Aerial view of typical canal diversion system on river (Spragg Canal headworks) (image from $h t t p s: / / w w w . y o u t u b e . c o m / w a t c h ? v=p 6 Z j 6 N H f 6 Y w$ ) 


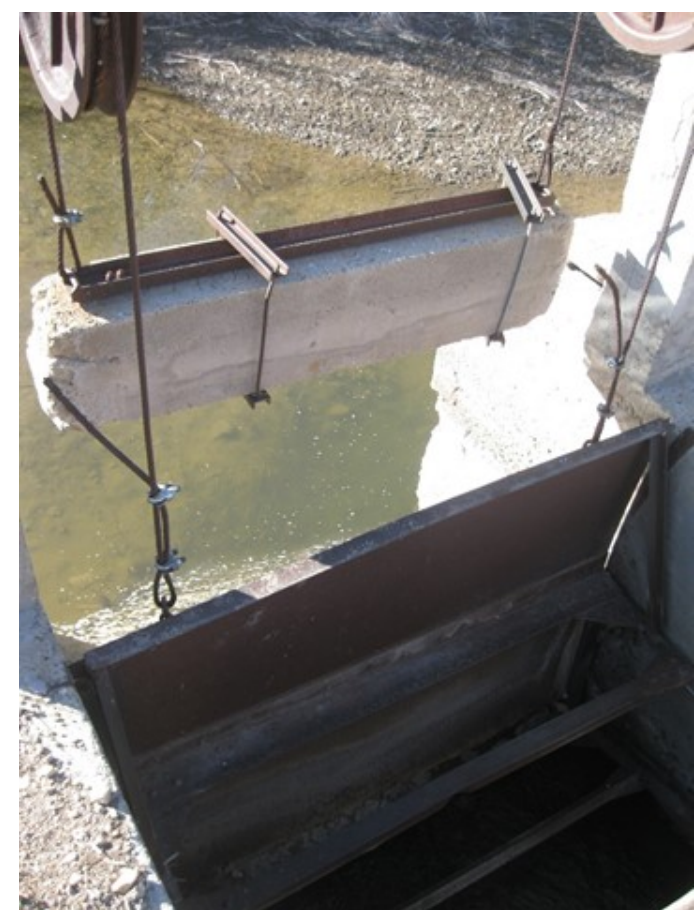

Figure 3. Danaidean gate in WRID

Water orders were filled as follows:

1. Ditchtenders took water orders from customers. Some water orders came straight to the WRID office.

2. Ditchtenders turned in water cards every day at 11 a.m. The summary reports of daily allocations (same as the delivered volume) were based on the compiled information from all the water cards.

3. A daily water schedule was allocated to all canal systems and direct turnouts according to the determined natural base flow by the water master. A scheduling meeting was held every afternoon (at 1:00 p.m.) with the water master and ditchtenders to analyze the next day's customers' water requests compared to the determined natural flow.

\section{INITIAL MODERNIZATION PLAN}

The existing system in WRID had aging infrastructure, no automated control, and no remote monitoring or control. In 2009, ITRC completed an irrigation modernization plan of WRID. The report focused on water measurement and control system improvements, and a total of twenty sites were included in the recommendations. The recommendations were intended to provide benefits for WRID and its customers by improving the accuracy of measured diversions from Walker River and enhancing the real-time control capabilities of water managers. The recommended system improvements would also provide a foundation for future modernization programs and improved transparency of water management in the District. Completion of final designs required some additional information such as local survey data and the preparation of drawings, in addition to an evaluation and field testing of communication options. To date, twelve of the twenty sites have been completed. 
An automated flow control gate package was recommended for fifteen sites in the original report.

The automated flow control gate package was to consist of:

1. Replogle flume (built from concrete) to replace the existing Parshall flume(s)

2. Self-contained motorized slide gate(s) in a district-standard configuration

3. SCADA Remote Terminal Unit (RTU) for automatic control of the slide gate(s) and communication with the office base station in Yerington, including industrial controller, communications, and solar power system

4. Various modifications to the existing spill structures (depending on site conditions)

Water Management Strategies. Implementation of the water gauge improvement projects created new management capabilities for water managers in WRID. The key strategies include the following:

- Control of diversions based on maintaining a constant target flow rate from canal headworks along the Walker River to match ordered demand for each canal system. Each canal headworks is equipped with new automated flow control gates and control systems for this purpose.

- The start of each canal is equipped with an upgraded water measurement device to be used in the new automated control system. Accurate measurement of canal diversions is important for proper management of scarce water resources. Knowing the actual amount of water delivered to the canals allows for a more complete understanding of the water demands in the system, and makes water records for individual accounts more precise. The flow rates and volumes of water delivered to the different canal systems is also critical information for water users in assessing and upgrading their own on-farm water management.

- New SCADA capabilities facilitate real-time remote monitoring of conditions throughout the Walker River Basin. Changes to canal flows can be made at specified times with accurate measurement of the current and historical flow rate in cubic feet per second (CFS), as well as the delivered volume in acre-feet $(A F)$. The water operations and record-keeping practices have been simplified.

- $\quad$ One person in the office can observe flows at key points throughout the service area; eventually, information from storage reservoirs will also be available. This central water manager makes decisions on a more frequent basis as part of a real-time and coordinated approach to water distribution throughout WRID’s points This involves the new automated hardware at the canal headworks, but also more significantly, active, real-time management of the system.

- Existing flashboard check structures were evaluated and prioritized for upgrading with longcrested weirs and cross-regulating structures. The improved canal water level control at turnouts means that large changes in canal flow no longer affect the system's ability to provide steady and measureable water deliveries. Operators can run lower or higher canal flows in order to meet irrigation demands while keeping more constant turnout flow rates.

\section{PACKAGE COMPONENTS}

As previously discussed, at turnouts from the river, the existing slide gates were removed and replaced with a new headgate automation package. The objective was to have a districtstandard slide gate and actuator package in WRID at all district canal headings. Specifications for the various components are discussed below. 
Replogle Flume. Properly designed, constructed and maintained water measurement devices are a key component of the proposed irrigation modernization improvements in WRID. In addition, accurate flow measurement structures were required for integration with the new automated flow control gates. The Replogle flume (e.g., broad-crested weir, ramp flume or long-throated flume) is a flow measurement device with a proven track record and thousands of successful installations in irrigation districts. These structures were installed at the headworks of each canal system identified in the plan.

In many locations, the Replogle flume was replacing an existing Parshall flume. These existing flumes were typically made of steel; they were corroding and had issues with moss growth. Many had settled and were no longer at the elevations necessary for proper flow measurement. The structures were designed for capacities significantly higher than are typically seen in the canals, reducing their accuracy at most of the operating flow rates. Additionally, the flumes did not have stilling wells for automated monitoring capabilities. An example of a pre-modernization Parshall flume is shown in Figure 4.

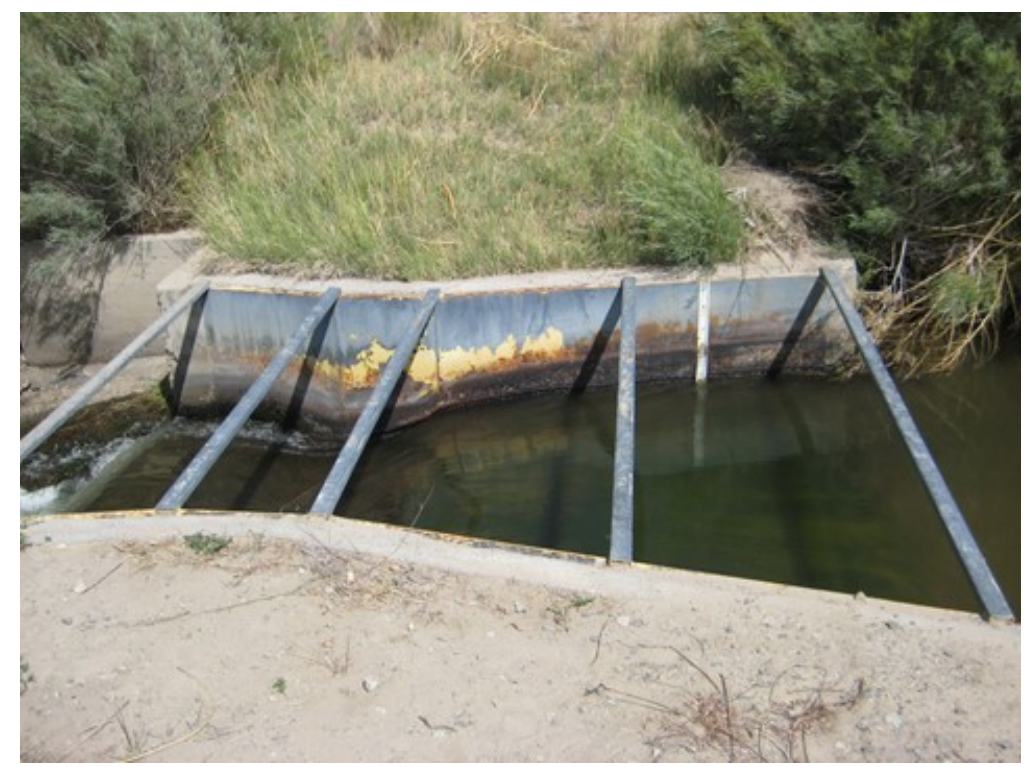

Figure 4. Example existing Parshall flume in WRID

An advantage of installing new Replogle flumes in the WRID canals is that they will require minimal maintenance except for periodically checking the site to clean moss off the concrete ramp. The flumes are also relatively vandalism-resistant. It is also easy to integrate these flumes into the proposed automation and SCADA system.

The Replogle flume will provide an accurate measurement of flow rate. As with the Parshall flumes, the Replogle flume allows for rapid stabilization of flows when the gates are changed and rapid feedback to the RTU controlling the radial gates. The operator is able to monitor the flow rate from the district office and change the target flow rate, and also has the option of overriding the automatic function and manually controlling the gates.

Before a final design decision could be made about the suitability of Replogle flumes at each of the identified locations, however, topographic survey data was collected and analyzed to 
determine if there was enough hydraulic head available. Additionally, records and site conditions were analyzed to determine the flow range for measurement in the flumes. Figure 5 shows an example of the measurement structures installed in the district.

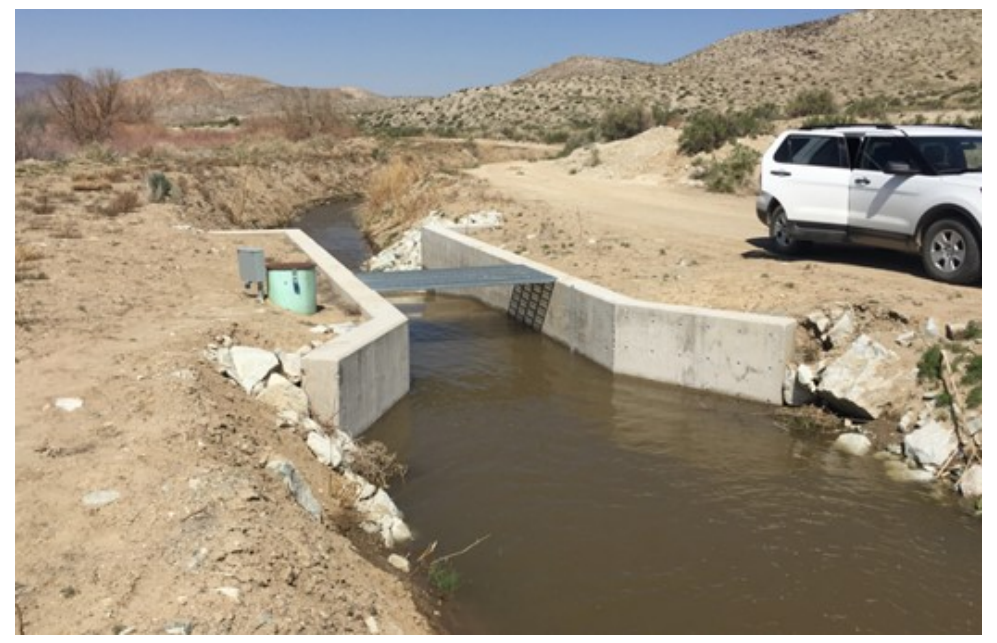

Figure 5. Concrete Replogle flume built in a rectangular cross-section on High Canal

Fabricated Slide Gate. The slide gate(s) required the following specifications:

- Series 8200 Fabricated Slide Gate (by Fresno Valves and Casting Inc., Selma, California) or approved equivalent

- Gate material (frame, slide and reinforcing): aluminum

- Stem material: stainless steel

- Flat back mount (secured to either a concrete headwall or angle iron)

- 3-sided J-seals (sides and top)

- Flush bottom seal

In order to fabricate the gates, the manufacturer required information such as the opening width and frame height. The self-contained frame design can be mounted in place of the existing tandem wooden headgates using either anchor bolts into the existing concrete walls or anchoring to new pieces of angle iron that are mounted to the concrete walls.

Electric Motor Gate Actuator. The electric motor actuator required the following specifications:

- Rotork IQ Series or approved equivalent

- Series IQD10, multi-turn [Direct current, 24 VDC]

- Local controls (local/stop/remote)

- Internal position sensor with 4-20 mA AO or Modbus Interface Card (2-wire RS485)

- Torque switch protection and over-temperature protection

- Side mounted hand wheel

- Solar-powered

The Integrator was responsible for all the connections from the actuator to the control system and for the design and installation of the solar power system. 
Automation and SCADA System. Automation and SCADA are valuable tools for enhancing water management. The automation and SCADA component of this project involved the design, deployment, calibration, documentation, and verification of industrially-hardened hardware and software for new canal control and measurement. This system can be remotely accessed in realtime from a base station computer and mobile laptops running specialized human-machine interface (HMI) software.

The new WRID automation and SCADA system has improved the reliability and flexibility of water deliveries throughout the service area. Other benefits of automation and SCADA include real-time water accounting, upgraded record-keeping capabilities for historical analysis and forecasting, and faster response times to user inputs and alarms. Future web-based reporting for water use or water quality datasets will also be facilitated by this well-designed automation and SCADA system.

The implementation of the WRID automation and SCADA system involved a series of steps:

1. Radio testing and evaluation of practical, cost-effective communication options

2. Presentation to district staff and board members of the Water Gauge Improvement Project and decisions about the scope, schedule, and budget for implementation

3. Meetings and field visits to selected sites to finalize details of the hardware requirements, along with any structural modifications

4. Preparation of the final Request for Proposals (RFP)

5. Hardware installation, implementation, calibration, testing, etc.

6. Field verification

7. Training and on-site service support

The use of robust equipment and software conforming to standardized specifications, along with some basic rules and practical techniques, ensures the implementation of a properly engineered automation and SCADA system. This type of system is reliable and can be expanded in the future. The following requirements were used to design the new WRID automation and SCADA system:

- Open system architecture

- A robust high-speed data radio network

- Industry-standard hardware components with Windows-based software

- $\quad$ System scalability

- High system reliability with redundancy of critical systems

Figure 6 shows a screenshot from the current SCADA system. The screen shows some details on the monitoring and control on the sites. 


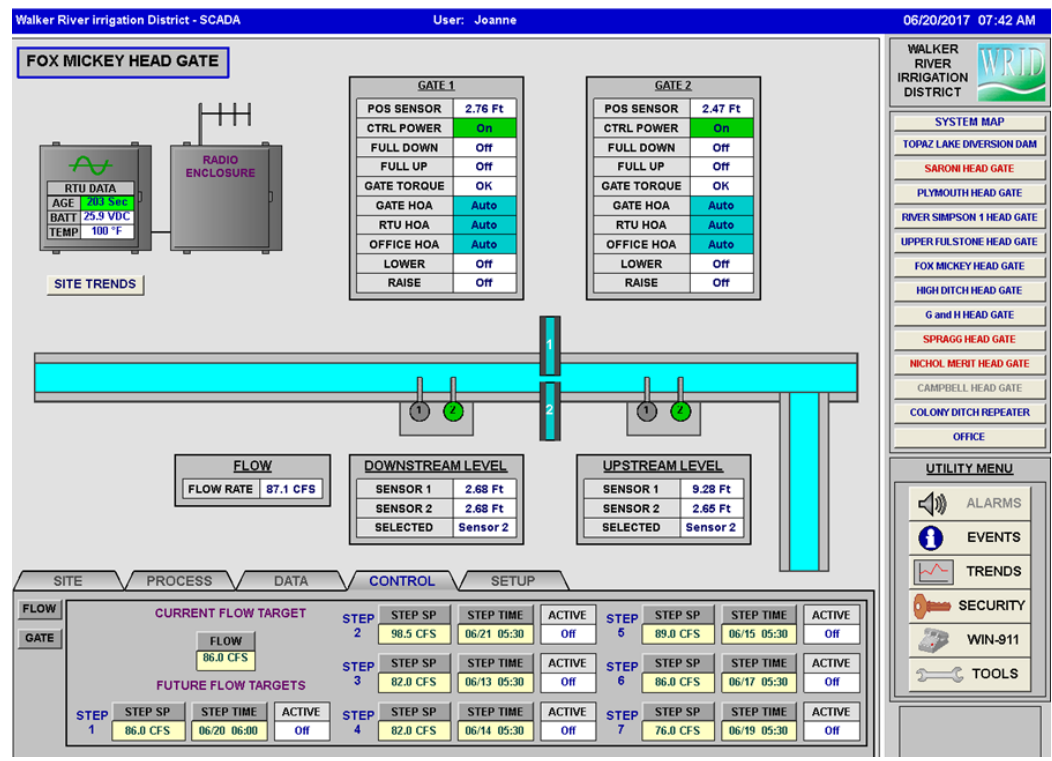

Figure 6. Example screenshot of WRID’s SCADA system

All sites are solar-powered due to their remote locations. The solar power systems were designed to ensure power is available throughout the irrigation season despite periods of inclement weather.

ITRC Flap Gate for Automatic Spill. Spill structures were updated at a number of canal headworks sites (see Figure 7). In many of these sites there were several feet of drop in the water surface between the canal and the river where the spill was returned. In these places, the recommendation was to install an ITRC flap gate to provide a constant water level (within $\pm 1.5 \mathrm{~cm} / 0.05 \mathrm{ft}$ ) while serving as an automatic continuous spill.

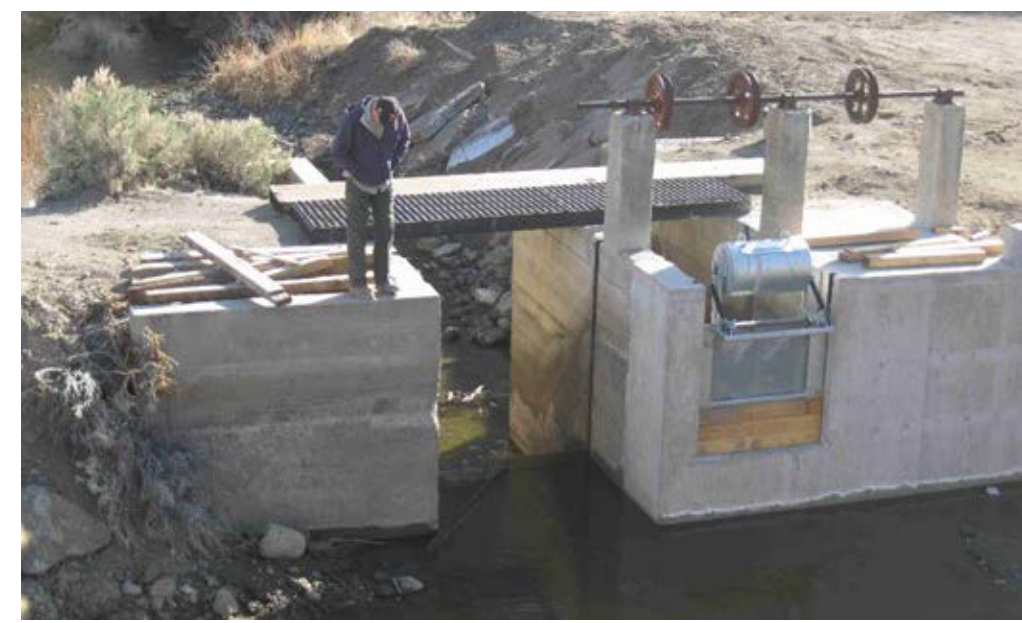

Figure 7. Flap gate installed in the Saroni Canal

The justification for upgrading the existing flashboard spill structures was that at the same size (i.e., the same width), the ITRC flap gate can pass significantly more water while maintaining


cubic meters per second (CMS) (10 CFS) with a depth of about 30-cm (1 ft) (head) on the weir, 
and the same weir could pass about 0.85 CMS (30 CFS), but the water depth would have to

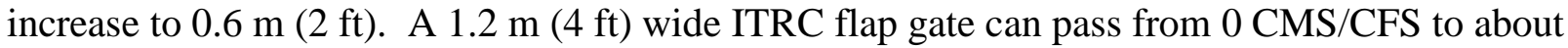
1.4 CMS (50 CFS) with only minimal changes in the upstream water level.

There are important operational justifications for having continuous spills upstream of the automated flow control gates. The automated flow gates do not have to move as frequently if operators can always divert more water than is required for irrigation demands. Due to the short distance, it has no effect on the overall amount of water diverted from the river because the 'excess' water is immediately returned to the same reach of river. In addition, the continuous spills provide an inherent safety feature in the event there are any problems with the gate automation.

A spreadsheet design program allows users to customize the gate size and weight for the desired location. The updated design spreadsheets are available at www.itrc.org/reports/flapgate.htm. ${ }^{1}$

\section{MODIFICATIONS TO PACKAGE}

As the project has progressed, the standard package has changed only slightly. Primarily, components have been updated to reflect current technology and the evolving needs of the district. One major component that has been added to the package at certain sites is the inclusion of sediment control structures. The method of diverting a majority of the river flow into a canal and then spilling the unneeded portion back to the river causes large sediment loads to enter the canal systems. The initial spill designs included a sluice gate with the ITRC flap gate to help direct lowflowing sediments back to the river, rather than into a canal system. The incorporation of sediment control structures has proven effective at further reducing the sediment load within the canal systems. Two types of sediment control structures have been installed in the district:

1. Settling basin. This consists of a large basin with a long (in length), but short (in height) wall at the end. The basin has a low velocity, causing sediments to fall out of suspension. The wall prevents the low-lying sediments from continuing downstream. The basin requires periodic maintenance to remove the sediment.

2. Spill structure sediment wall. This consists of a diagonal wall just downstream of the sluice gate that spills to the river. The wall ensures the sediment-laden flows at the bottom of the canal are directed to the sluice gate spill structure, and back to the river. Experience has shown that the sediment builds up in the spill channel, requiring periodic maintenance of the spill channel.

The sediment control structures have proven to be effective. The additional maintenance required by the structures is offset by the continual maintenance and issues throughout the canal systems associated with large sediment loads.

Modifications have also been made to the district package to reflect updated knowledge and equipment. Some examples are given below:

\footnotetext{
${ }^{1}$ The design spreadsheet provides no analysis of the structural soundness or integrity of a gate or of the supporting structure.
} 
- The existing solar sites were inventoried in 2016 and updated recommendations were given based on current off-grid solar site design specifications (IEEE 1013, 136, and 1562). Mainly, the solar panel sizes and battery capacities were increased to ensure the power supply could meet the system needs throughout the irrigation season despite periods of inclement weather.

- Insufficient grounding had caused some submersible pressure transducers to fail. A specification for proper grounding at each RTU was developed.

\section{PACKAGE COST}

The cost of the headworks package varies from approximately $\$ 150,000$ for a relatively simple site to approximately $\$ 300,000$ for sites with significant concrete work. Costs on some items can vary widely depending upon challenges with communications, decisions about who does the construction and gate installation work, un-anticipated structural problems, prevailing wages, etc. The following example, the Fox Mickey Headworks, is an example of a site at the higher end of the range, costing around $\$ 300,000$.

\section{EXAMPLE SITE: FOX MICKEY HEADWORKS}

The location of the Fox Mickey Headworks SCADA project at the diversion from the East Fork of Walker River is shown in Figure 8. The design capacity of the canal headworks is approximately 4 CMS (140 CFS), with an average capacity of 2.1 CMS (75 CFS).

The layout of the original water control and measurement infrastructure at the headworks of the Fox Mickey Canal is also shown in Figure 8. The configuration and function of the original structures consisted of:

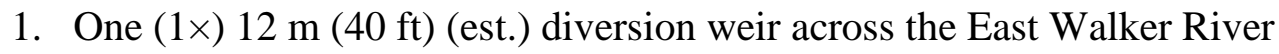

2. Two (2×) $2.4 \mathrm{~m}(8 \mathrm{ft}$ ) wooden slide gates (manually operated, usually left open)

3. One $(1 \times)$ spill structure with a $1.2 \mathrm{~m}(4 \mathrm{ft})$ flashboard bay and a $1.2 \mathrm{~m}$ (48-inch) slide gate

4. Two (2×) $2.3 \mathrm{~m}(7.5 \mathrm{ft}$ ) slide gates (left gate is wooden and right gate is steel) (manually operated)

5. One $(1 \times)$ spill structure with an 45 -cm (18-inch) slide gate

6. Two (2×) $1.8 \mathrm{~m}(6 \mathrm{ft})$ Parshall flumes for flow measurement

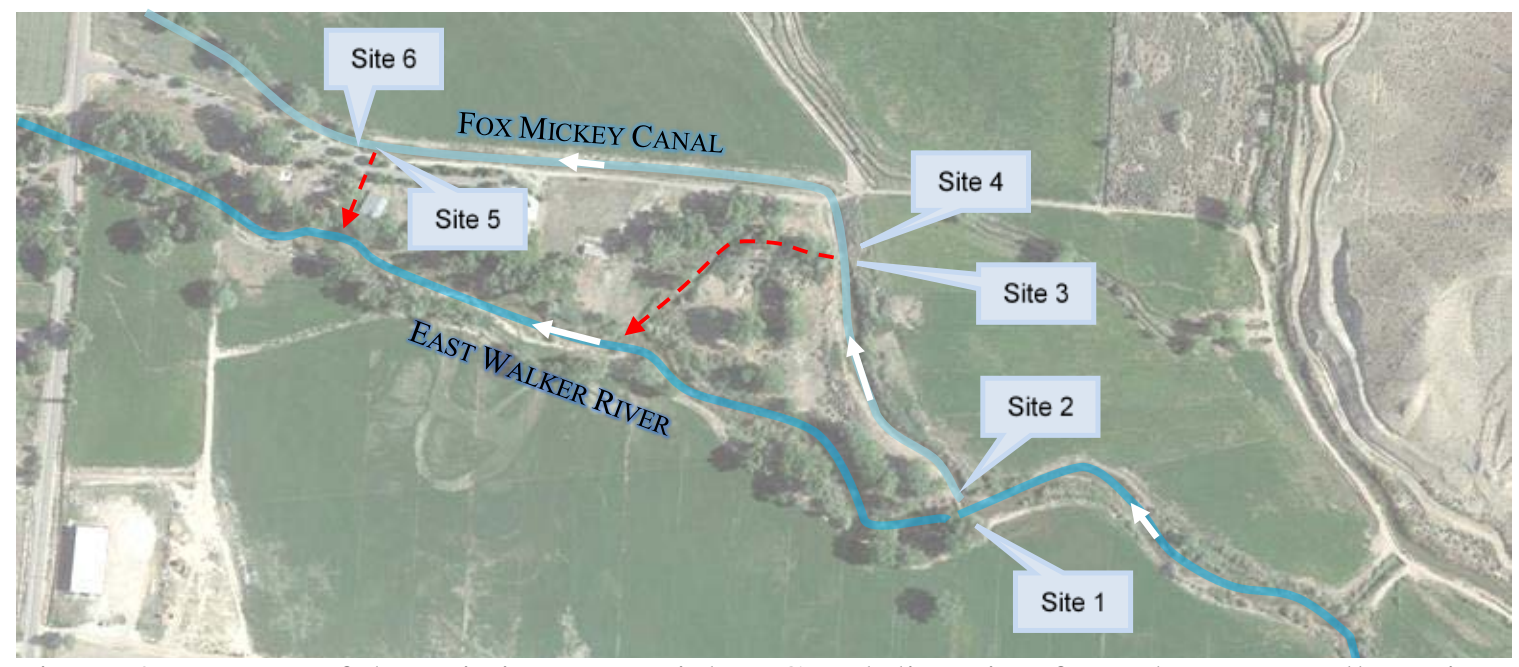

Figure 8. Layout of the existing Fox Mickey Canal diversion from the East Walker River 
The modernization improvements at the Fox Mickey Headworks involved the following features, with site numbers corresponding to those shown in Figures 8 and 12:

1. Adding a new $55 \mathrm{~m}(180 \mathrm{ft})$ long $\times 11 \mathrm{~m}$ (35 ft) wide settling basin and $15 \mathrm{~m}(50 \mathrm{ft})$ long sediment wall between Site 2 and Site 3 (structure shown in Figure 9, "Site 2a” in Figure 12). This basin reduces the sand and silt load that enters the canal system from the river. The Fox Mickey sediment basin filled in 2016 (the first year it was functional), requiring the district to remove the sediment to prevent the sediment from affecting upstream water levels.

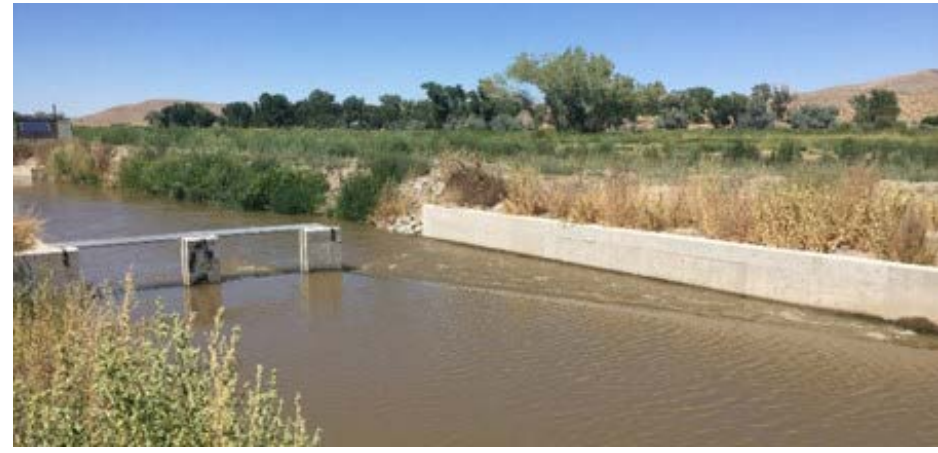

Figure 9. Settling basin and sediment wall on Fox Mickey Canal

2. Installation of an ITRC flap gate in the existing open spill channel at Site 3. The flap gate was designed with a capacity for continuous spill up to approximately 0.7 CMS (25 CFS) (approx. $1.2 \mathrm{~m} / 4 \mathrm{ft}$ wide and $0.6 \mathrm{~m} / 2 \mathrm{ft}$ deep).

3. Installation of a $12 \mathrm{~m}(40 \mathrm{ft})$ long sediment wall directly downstream of Site 3 to reduce the sediment load down the canal.

4. Replacement of slide gates at Site 4 with two new automated flow control gates $(72 \times 48$ Series 8200 Fabricated Slide Gates by Fresno Valves and Casting, shown in Figure 10) installed in a new reinforced concrete headwall structure, as well as an RTU, solar panel, and newly established communication with the district's headquarters in Yerington, Nevada for distributed control.

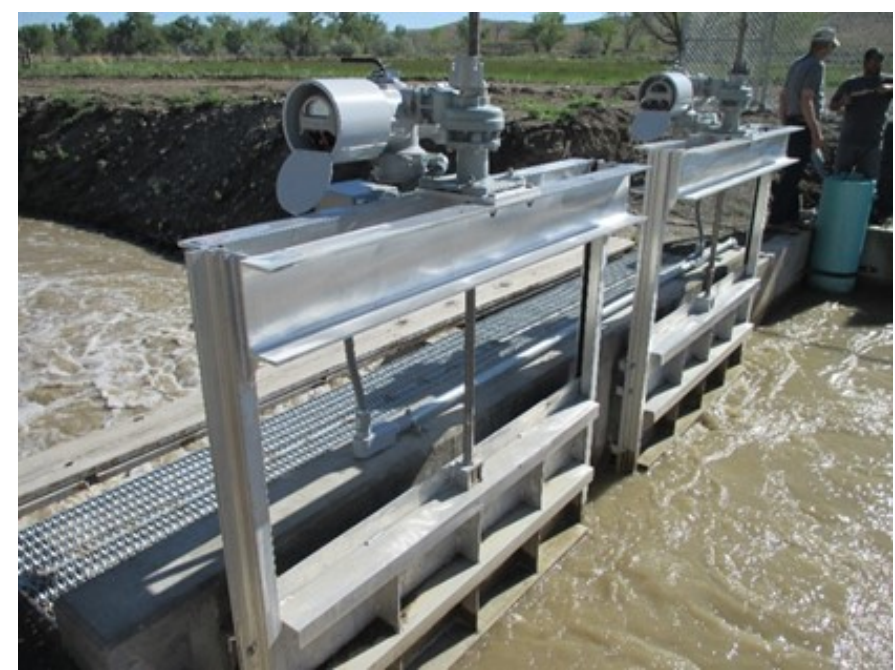

Figure 10. Automated gates on Fox Mickey Canal

5. Removal of the Parshall flumes at Site 6. 
6. Installation of a new Replogle flume with automated flow rate measurement that is connected to the slide gate system for automatic flow control (Figure 11). The new flow measurement structure was installed approximately $300 \mathrm{~m}$ (1,000 ft) upstream of the existing Parshall flume ("Site 6b" in Figure 12).

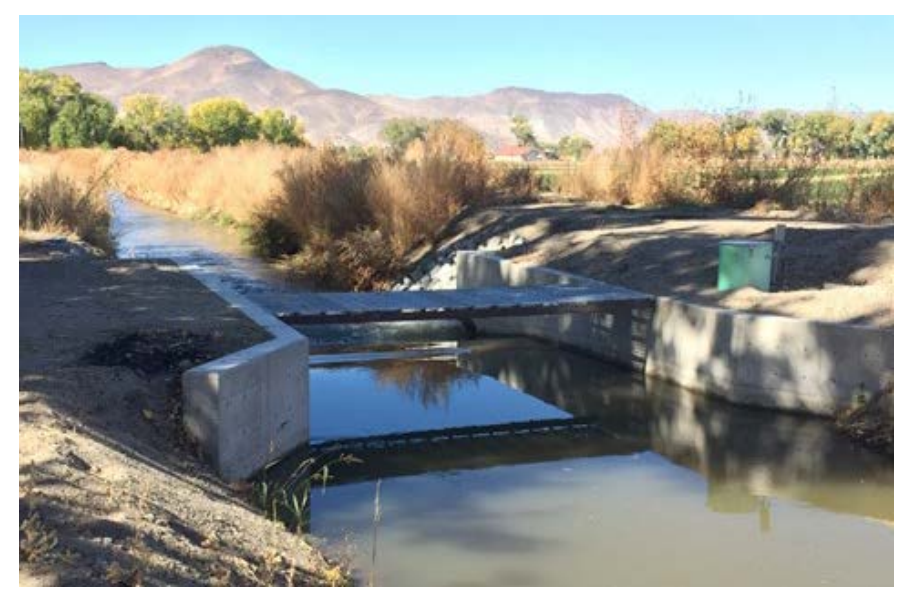

Figure 11. Replogle flume on Fox Mickey Canal

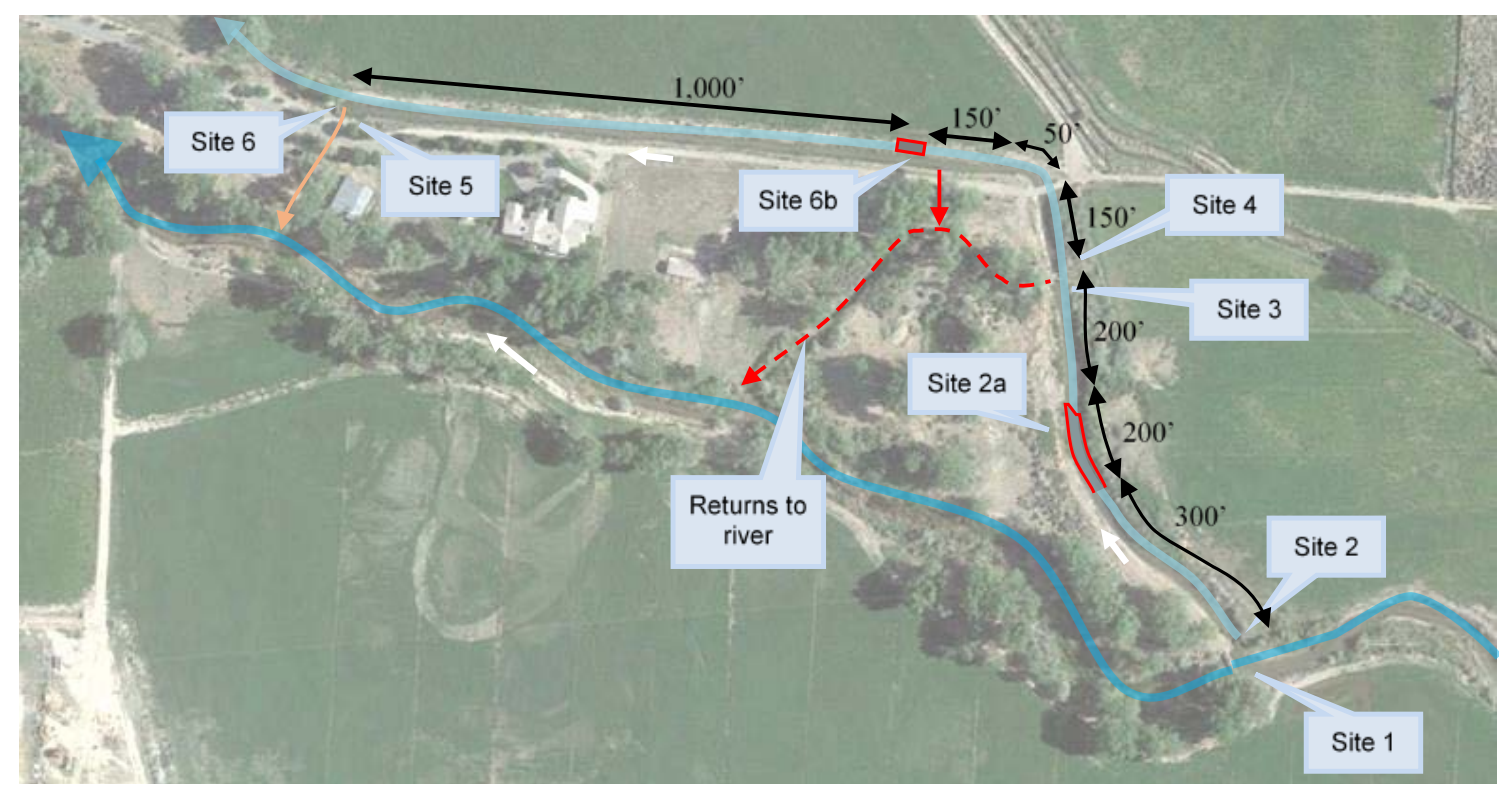

Figure 12. Layout of the proposed upgrades to the Fox Mickey Canal

7. Grading the canal from Site $6 \mathrm{~b}$ to Site 6 .

8. Flow rate target that is re-settable from the ClearSCADA HMI workstation at the headquarters office and from SCADA-equipped laptops

9. Solar-powered gates, automated control, and SCADA system (12/24 VDC)

10. District-standard hardware/software

11. Flow rate (CFS) and water level data (feet) transmitted to the base station at the WRID headquarters office every 1 minute via radio

12. On-site display of flow rate (CFS), upstream water level (feet), and other control parameters, in addition to local data logging and storage 
Automation and SCADA System Operations. An overview of the new automation and SCADA system components at the Fox Mickey Canal Headworks is shown in Figure 13.

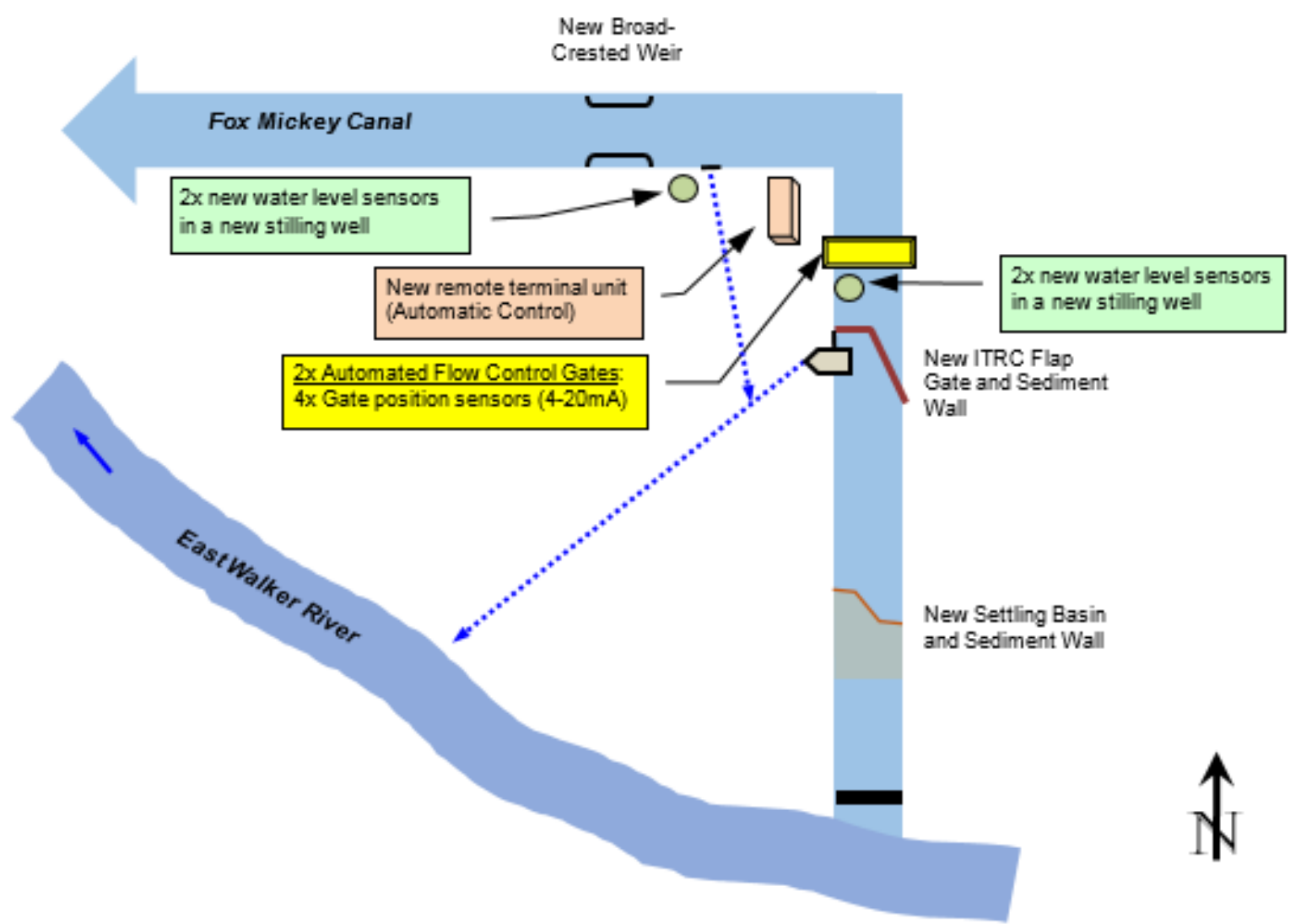

Figure 13. Schematic overview of the automation and SCADA improvements at Fox Mickey Canal

The main Remote Terminal Unit (RTU) was pre-assembled, bench-tested, and made ready for operation by the Integrator prior to delivery to WRID. Alteration, logic functions, metering, alarm, and all other control components used in the monitoring system are performed by the automation system. The “district standard” RTU consists of a stand-alone distributed control center with self-contained electronics and sensor systems including a graphical operator interface terminal. The control system consists of a SCADAPack 32/350 PLC or approved equivalent to control the timing of operation, gate alteration, control, and alarm functions, in addition to other specified equipment. A single PLC was used to control the gate.

Other components of the system included water level sensors, gate position sensors, an autodialer for emergency notification of alarm conditions (via the office HMI software), a battery backup system, and hand/off/auto selector switches and misc. electrical wiring. The water levels sensors upstream and downstream of the check structure (a total of four sensors) were provided and installed by the Integrator.

The automation and SCADA system for the Fox Mickey Headworks automated gates performs the following functions:

1. Automatically control flow based on a user-defined target flow rate 
2. Remotely change the target flow rate

3. Allow remote manual control of the slide gate(s) to move to a target gate opening(s)

4. Remotely monitor system status (positions, alarms, gate status)

5. Remotely monitor water levels in the pool upstream of the slide gates

6. Remotely monitor the canal flow rate(s) measured at the Replogle flume

7. Remotely change the operation from automatic to manual (if necessary)

8. Remotely (but via a secure mode) change key controller set points

9. Remotely select which of the two redundant sensors (for every measurement) should be considered the "primary" sensor for control purposes

The Fox Mickey Canal site has been completed and functional since summer 2016.

\section{OTHER DISTRICT PROJECTS}

As the initial plan has been implemented, updates have been made to the original designs to reflect updated knowledge and additional requirements. Also, approximately twenty additional sites and projects have been added to the original twenty sites, with fourteen of the original twenty completed to date (plus ten of the additional sites).

Other projects are planned and/or have been implemented in WRID, including:

- Long-crested weirs - Long-crested weirs provide automatic upstream water level control with no moving parts and minimal maintenance.

- Cross-regulating structures - Cross-regulating structures would be classified as an upstream water level control structure with precision capabilities somewhere between a flashboard structure and a long-crested weir. These structures are cost-effective to install in small canals, can maintain fairly constant upstream water levels, and provide flow rate estimates.

- Large (up to $1.5 \mathrm{~m} / 60$ inch) pipelines - Pipelines were necessary at certain locations throughout the district to reduce seepage (either to minimize water losses in the canal or to protect downhill structures) and prevent debris from entering the canal system, especially on steep hillsides.

- Reservoirs throughout the district for regulating river flows (planned) - Reservoirs will provide buffer storage to the district during the irrigation season. This will allow a more constant flow rate in the river to meet downstream legal flow requirements. Reservoirs can also provide short-term storage during storms to reduce peak flows and silt loads in the water. They will also provide a secondary benefit of recharging the groundwater basins (the district relies on conjunctive use).

\section{CONCLUSION}

WRID's system of remote monitoring and control has improved water delivery for water users within the district. ITRC and the district have implemented numerous new flow measurement, flow control and sediment control devices; installed new hardware and control equipment; and discussed water management strategies. The district has recognized the long-term value of proper engineering design and high-quality, off-the-shelf technology. ITRC has approached the modernization strategy by using the simplest device possible to meet the needs of a site. The district plans on continuing the modernization based on the success of the program to date. 